\title{
Does Obesity Affect Early Results after Coronary Artery Bypass Grafting?
}

\author{
Mahdi Aithoussa ${ }^{1}$, Noureddine Atmani ${ }^{*}$, Anis Seghrouchni ${ }^{1}$, Abdessamad Abdou1, \\ Younes Moutakiallah', Mehdi Bamous ${ }^{1}$, Siham Bellouize1, Fouad Nya', Zouhair Lakhal' \\ Abdedaim Hatim Ghadbane', Youssef Elbekkali', Abdelatif Boulahya' ${ }^{1}$
}

\footnotetext{
${ }^{1}$ Department of Cardiovascular Surgery, Mohammed V Military Teaching Hospital, Mohammed V University Souissi, Rabat, Morocco

${ }^{2}$ Department of Cardiology, Mohammed V Military Teaching Hospital, Mohammed V University Souissi, Rabat, Morocco Email: mahdiaithoussa@yahoo.fr, ‘dratmani@hotmail.fr, anisdr@yahoo.fr, abdessamadabdou@gmail.com, dryounes@hotmail.fr, mehdibamous@hotmail.com, lalla-siham3@hotmail.fr, fouad.nya@hotmail.fr, lakhalzouhair1@yahoo.fr, hatimabdedaim@yahoo.fr, youssefelb10@hotmail.fr, aboulahya7@yahoo.fr
}

How to cite this paper: Aithoussa, M., Atmani, N., Seghrouchni, A., Abdou, A., Moutakiallah, Y., Bamous, M., Bellouize, S., Nya, F., Lakhal, Z., Ghadbane, A.H., Elbekkali, Y. and Boulahya, A. (2017) Does Obesity Affect Early Results after Coronary Artery Bypass Grafting? World Journal of Cardiovascular Surgery, 7, 119-129. https://doi.org/10.4236/wjcs.2017.710014

Received: September 13, 2017

Accepted: October 28, 2017

Published: October 31, 2017

Copyright $\odot 2017$ by authors and Scientific Research Publishing Inc. This work is licensed under the Creative Commons Attribution International License (CC BY 4.0).

http://creativecommons.org/licenses/by/4.0/

\section{c) (i) Open Access}

\begin{abstract}
Background: The aim of this study was to quantify the effect of obesity on early results after coronary artery bypass grafting (CABG). Methods: A retrospective cohort study of patients underwent isolated CABG from January 2000 through December 2012 was conducted. 586 patients were classified into two groups: Obese $(\mathrm{n}=100) \mathrm{BMI} \geq 30 \mathrm{~kg} / \mathrm{m}^{2}$ and non-obese $(\mathrm{n}=486) \mathrm{BMI} \leq$ $30 \mathrm{~kg} / \mathrm{m}^{2}$. Results: The obese patients included more women $(\mathrm{p}<0.01)$, hypertensives $(\mathrm{p}=0.01)$ and dyslipidemics $(\mathrm{p}=0001)$. The CPB, aortic champ times and number of bypass graft were similar between the groups $(p=0.35, p$ $=0.51$ and $\mathrm{p}=0.59$ respectively). Also the composite of in-hospital mortality and postoperative complication didn't differ between the groups. The incidence of perioperative myocardial infarction, and need for inotropic drugs or IABP were significantly less in obese patients $(p=0.028, p=0.031$ and $p<$ 0.01 respectively). Conclusions: The current study showed that obesity is not a risk factor of adverse events after CABG and continuous to give another aspect of the "obesity paradox".
\end{abstract}

\section{Keywords}

Obesity, Coronary Artery Bypass Grafting, Morbidity, Mortality

\section{Introduction}

Obesity is a serious public health problem in most occidental countries [1] [2]. The prevalence of obesity has also increased in affluent and developing societies 
because of change in habit diet [2] [3]. Epidemiologic data indicate that obesity is associated with atherosclerotic heart disease [4] [5]. Most studies comparing the repercussion of overweight and obesity on short and long-term outcomes in patients undergoing myocardial revascularization found that obesity had negative effect on results after cardiac surgery [6] [7] [8]. But in recent years, acceptable results have been documented due to progress in medical management. This study compared the short outcomes between obese and non-obese patients who underwent coronary artery bypass grafting (CABG).

\section{Methods}

The study was a retrospective cohort analysis of patients who underwent coronary artery bypass graft at our institution. The institutional local medical ethic committee approved the study protocol. All patients who underwent a first isolated CABG operation from January 2000 through December 2012 were considered eligible for the study. We excluded patients who underwent off-pump CABG, concomitant valve surgery, or aortic root replacement in order to ensure to get remained population homogenous.

According to world health organization obesity definition, the patients were divided into 2 groups: non obese patients with BMI (body mass index) $<30$ $\mathrm{kg} / \mathrm{m}^{2}$ and obese patients with $\mathrm{BMI} \geq 30 \mathrm{~kg} / \mathrm{m}^{2}$.

Patients demographics, preoperative variables, intraoperative and postoperative variables were obtained from our institutional database.

Standard operating strategy on cardiopulmonary bypass (CPB) was utilized. After Induction of anesthesia and preparation, a median sternotomy was performed. The conduits were harvested. CPB was established using a roller pump with a membrane oxygenator after systemic heparinization (300 UI/ $\mathrm{kg}$ ) to obtain active clotting time kept over 450 seconds. Surgery was performed under mild hypothermia $\left(34^{\circ} \mathrm{C}\right)$. Myocardial protection was achieved with antegrade blood cardioplégia via the root. Repeat doses were given every 20 minutes. Topical cooling was used to enhance myocardial protection.

Distal coronary anastomoses were performed on a still heart. After completion of distal anastomoses and rewarming, the aortic cross clamp was removed, and the proximal ends of the vein grafts were anastomosed to the aorta using a partial occluding clamp. Subsequently, the heart was allowed to perfuse and the patient was weaned from CPB. The procedure was achieved in the standard fashion and the patient was transferred to the intensive care unit (ICU).

\subsection{End Points of the Study}

The operative mortality was defined as death from any cause within 30 days after operation or any interval if the patient was not discharged. The morbidity in cluded the following complications occurring during the hospital stay period. Acute myocardial infarction (AMI) was defined as the appearance of new $Q$ waves on Electrocardiogram, increased level of creatine kinase-MB isoenzyme $\geq$ 
$100 \mu \mathrm{g} / \mathrm{l}$.

The criterion for postoperative renal failure was an increase of at least $50 \%$ of the baseline serum creatinine level. A postoperative stroke was defined as a clinical evidence of a focal neurologic deficit with a radiologic defect on imaging techniques.

Low cardiac output syndrome (LCOS) was identified as cardiac index lower than $2 \mathrm{l} / \mathrm{min} / \mathrm{m}^{2}$ which need intra aortic balloon pump (IABP) or excessive inotropic support. The criterion for postoperative infection was the presence of a positive blood culture of the sputum associated with a radiological infiltration.

\subsection{Statistical Analysis}

SPSS version 19.0 (SPSS Inc, Chicago, IL, USA) was used for statistical analysis.

Continuous parameters are described by mean \pm Standard Deviation or median with interquartile range, whereas categorical data are exposed as frequencies and percentages.

Comparisons of numerical variables between two groups were performed with student's $t$ test or Mann-Whitney $U$ test if not meeting the normal distribution. Differences in proportion were compared with a chi-square test or Fisher exact test, as appropriate. Statistical significance was set as $\mathrm{p}<0.05$.

\section{Results}

Five hundred and eighty six patients were included in the present study. There were $486(82.9 \%)$ non-obese patients $\left(\mathrm{BMI}<30 \mathrm{~kg} / \mathrm{m}^{2}\right)$ and $100(17.1 \%)$ obese $\left(B M I \geq 30 \mathrm{~kg} / \mathrm{m}^{2}\right)$. the mean age of the patients was similar in two groups $58.9 \pm$ 8.7 years and $58.5 \pm 9.1$ years $(\mathrm{p}=0.64)$. Our patients are comparable in terms of age to the patients in Ardeshiri's study [9], which represents a sample and a profile of developing countries. The number of female patients in obese groups (26.26\%) was higher than in non-obese group $(11.3 \%)$ ( $\mathrm{p}<0.01)$. They were more hypertensive and dyslipidemic patients in the obese group $(\mathrm{p}<0.01)$. No statistical difference was found between groups in terms of diabetes mellitus $(\mathrm{p}=$ $0.76)$ but more smokers were observed in non-obese patients $(\mathrm{p}<0.01)$. The prevalence of co-existant comorbidities was similar into 2 groups. Also, the coronary lesion distribution was similar between obese and non-obese patients. Unlike peripheral vascular disease (PVD) prevailed in the non-obese patients $(21.8 \%)$ vs. $(7.7 \%)(\mathrm{p}<0.01)$. The preoperative demographic characteristics of the patients are given in detail in Table 1 and Table 2.

Table 3 showed operatives and postoperatives data of the two groups. When the intraoperative characteristics of the patients are compared the mean $\mathrm{CPB}$, aortic cross clamp and operative times were similar in both groups. Also, the mean number of bypass grafts was similar $(\mathrm{p}=0.53)$. They are no differences in the postoperative complications. When postoperative outcomes are explored, ICU stay was longer in non obese patients $(\mathrm{p}=0.014)$. 
Table 1. Non-significant preoperative demographic characteristics of the patients.

\begin{tabular}{lccc}
\hline \multicolumn{1}{c}{ Variable } & Obese n $=100$ & No obese 486 & P value \\
\hline Age (years) & $58.9 \pm 8.7$ & $58.5 \pm 9.1$ & 0.64 \\
Diabetemellitusn (\%) & $49(49 \%)$ & $246(50.6 \%)$ & 0.76 \\
Prior CTI n (\%) & $8(8 \%)$ & $23(47 \%)$ & 0.21 \\
Unstable Angina n (\%) & $46(46 \%)$ & $180(37 \%)$ & 0.09 \\
History of CVA n (\%) & $1(1 \%)$ & $7(1.4 \%)$ & 0.73 \\
Renal dysfunction n (\%) & $7(7 \%)$ & $31(6.3 \%)$ & 0.81 \\
Peroperative pulmonary disease & $12(12 \%)$ & $68(13.9 \%)$ & 0.59 \\
LVEF (\%) & $56 \pm 12$ & $53.3 \pm 13.4$ & 0.53 \\
Extent of CAD n (\%) & & & - \\
$\quad$ - Left main disease & $16(16 \%)$ & $82(16.8 \%)$ & 0.81 \\
$\quad$ - 1 vessel & $12(12 \%)$ & $42(8.6 \%)$ & - \\
- 2 vessel & $23(23 \%)$ & $152(31.2 \%)$ & - \\
- 3 vessel & $65(65 \%)$ & $292(60 \%)$ & - \\
Creatinine (mg/l) & $10.6 \pm 3.3$ & $11 \pm 7.8$ & 0.37 \\
Euroscore & $2.9 \pm 2.6$ & $3.2 \pm 2.7$ & 0.27 \\
\hline
\end{tabular}

CAD: cardiac artery disease. CTI: coronary transluminal intervention. CVA: cerebrovascular attack. LVEF: left ventricular ejection fraction.

Table 2. Significant preoperative demographic characteristics of the patients.

\begin{tabular}{lccc}
\hline \multicolumn{1}{c}{ Variable } & Obese $\mathbf{n}=100$ & No obese 486 & P value \\
\hline Women n (\%) & $26(26 \%)$ & $55(11.3 \%)$ & $<0.001$ \\
BMI (kg/m $)$ & $31.3 \pm 1.7$ & $25 \pm 2.7$ & $<0.001$ \\
Hypertension n (\%) & $58(58 \%)$ & $190(39 \%)$ & $<0.001$ \\
Smooking n (\%) & $45(45 \%)$ & $297(61.1 \%)$ & 0.003 \\
Hyperlipidemia n (\%) & $47(47 \%)$ & $157(32.2 \%)$ & 0.005 \\
Prior MI <30 days n (\%) & $21(21 \%)$ & $154(30.8 \%)$ & 0.03 \\
NYHA fonctionnal class III-IV n (\%) & $6(6 \%)$ & $75(15.4 \%)$ & 0.01 \\
Low LVEF (<0.4) & $12(12 \%)$ & $101(20.7 \%)$ & 0.04 \\
SAP (mmHg) & $131.4 \pm 21.4$ & $125.4 \pm 16$ & 0.01 \\
DAP (mmHg) & $74.5 \pm 11$ & $70.5 \pm 9.7$ & 0.001 \\
Peripheral vascular disease n (\%) & $7(7 \%)$ & $106(21.8 \%)$ & 0.001 \\
Number of coronary risk factor & $2.99 \pm 1.04$ & $1.94 \pm 0.9$ & $<0.001$ \\
\hline
\end{tabular}

BMI: body mass index, DAP: diastolic arterial pressure. LVEF: left ventricular ejection fraction. MI: myocardial infarction, SAP: systolic arterial pressure. 
Table 3. Operative and postoperative characteristics of the patients.

\begin{tabular}{|c|c|c|c|}
\hline Variable & Obese $n=100$ & No obese 486 & $P$ value \\
\hline No elective surgery $n(\%)$ & $4(4 \%)$ & $28(5.7 \%)$ & 0.48 \\
\hline CPB time (min) & $115 \pm 37.8$ & $112 \pm 37$ & 0.35 \\
\hline Cross clamp time (min) & $68.8 \pm 25.7$ & $66.9 \pm 27.7$ & 0.51 \\
\hline Operative time $(\min )$ & $245.5 \pm 47$ & $243.4 \pm 56$ & 0.73 \\
\hline MV (hours) & $9(6-16.75)$ & $9(6-17)$ & 0.89 \\
\hline ICU stay (hours) & $57 \pm 22$ & $66.7 \pm 69$ & 0.014 \\
\hline Postoperative hospital stay (days) & $11(9-14)$ & $11(9-13.5)$ & 0.74 \\
\hline Inotropicdrug $\mathrm{n}(\%)$ & $6(6 \%)$ & $67(13.7 \%)$ & 0.031 \\
\hline IABP n (\%) & $3(3 \%)$ & $57(11.7 \%)$ & 0.009 \\
\hline LOS n (\%) & $6(6 \%)$ & $51(10.5)$ & 0.16 \\
\hline Postoperative RF n (\%) & $12(12 \%)$ & $32(6.6 \%)$ & 0.06 \\
\hline Reoperation for bleeding $\mathrm{n}(\%)$ & $8(8 \%)$ & $26(5.3 \%)$ & 0.3 \\
\hline Pneumonia/mediastinitis & $14(14 \%)$ & $48(9.8 \%)$ & 0.22 \\
\hline Postoperative AMI n (\%) & $6(6 \%)$ & $68(13.9 \%)$ & 0.028 \\
\hline Stroke & $2(2 \%)$ & $3(0.6 \%)$ & 0.17 \\
\hline $\mathrm{RBC}$ transfusion & $56(56 \%)$ & $239(49.1 \%)$ & 0.22 \\
\hline Blood lost/24hours & $475(350-725)$ & $500(350-725)$ & 0.63 \\
\hline MOF & $1(1 \%)$ & $10(2 \%)$ & 0.47 \\
\hline Number of coronary bypass graft & $2.43 \pm 0.82$ & $2.38 \pm 0.78$ & 0.53 \\
\hline $\mathrm{CPK} \mathrm{mb}$ & $56.3 \pm 39$ & $63.8 \pm 61$ & 0.41 \\
\hline Troponine & $0.9(0.2-3.8)$ & $1.47(0.3-3.9)$ & 0.078 \\
\hline 30 day mortality & $6(6 \%)$ & $23(4.7 \%)$ & 0.59 \\
\hline
\end{tabular}

AMI: acute myocardial infarction. CPB: cardiopulmonary bypass. IABP: intra-aortic balloon pump. ICU: intensive care unit. LOS: low out pout syndrome. MOF: multivisceral organ failure. MV: mechanical ventilation. RBC: red blood cell. RF: renal failure.

AMI occurred markedly in non obese patients $(13.9 \%$ vs. $6 \% ; \mathrm{p}=0.028)$. They were no differences in stroke, renal failure, infection, postoperative hospital stay and re-exploration for bleeding. Non obese patients developed LCOS more than obese patients $(10.5 \%$ vs. $6 \% ; \mathrm{p}=0.16)$ but it didn't reach statistical significance. This explained excessive inotropic use $(13.7 \%$ vs. $6 \% ; \mathrm{p}=0.031)$ and required IABP more than obese patients $(11.7 \%$ vs. $3 \%$; $<<0.01)$. There was no difference in in-hospital mortality ( $6 \%$ in obese vs. $4.7 \%$ in non obese; $p=0.59$ ).

The amount of chest tube drainage was similar in both groups $(\mathrm{p}=0.63)$. And the need for Red Blood Cell transfusion was similar also $(\mathrm{p}=0.22)$.

\section{Discussion}

The most important finding of this study showed that obese patients don't have greater morbidity and mortality than normal weight patients after CABG. Our patients are comparable in terms of age to the patients in Ardeshiri's study [9], which represents a sample and a profile of developing countries. These findings 
are consistent with some trials which have suggested that obese patients coronary artery disease actually have better outcomes after CABG [10] [11] [12] [13]. Recent studies have shown that obese patients fair better after open heart surgery [12] [14] [15]. This relationship of obesity to postoperative results is complex and called the obesity paradox.

Our study showed also a high prevalence of obesity in cardiac artery disease patients submitted for CABG (17.1\%), which is in agreement with some previous studies [9] [16] [17]. Despite socioeconomic disparity, even in developing countries, an increased tendency towards obesity has been observed [18].

In the era of risk stratification and informed consent, commonly applied estimation of open heart surgical risks may not adequately assess obesity as a risk factor in various scoring system [19] [20]. Also, the highly predictive Euroscore does not include BMI stratification for cardiac surgical [21]. Traditionally, obesity has been viewed as a major risk factor for postoperative mortality and morbidity in patients undergoing CABG [20] but many studies have failed to demonstrate that obesity is a determinant risk factor after CABG [13] [22] some studies found a higher incidence of mortality in the postoperative and mid-term follow-up after CABG in obese patients [23] [24], whereas others did not find this association and reported a lower mortality in obese patients undergoing CABG [25] [26].

In recent observational retrospective study published by Shahabuddin [13], in hospital mortality rate was $0.8 \%$ in obese patients who underwent CABG. This is explained by marked improvements in medical management of high risk patients who can be operated with acceptable operative mortality. In our case series, demographic data of obese patients differ when compared with non-obese patients. Obese patients have increased prevalence for hypertension and diabetes mellitus, that is consistent with previous reports [8] [27]. We found that female accounted for the majority of our obese patients than non-obese. This finding is consistent with other studies [9] [28]. The data on the prolonged mechanical ventilation in obese patients are conflicting. Saleh et al. [29] studied the risk factors of prolonged ventilation in patients undergoing $C A B G$ and they found that BMI $>35 \mathrm{~kg} / \mathrm{m}^{2}$ was a predictor of prolonged respiratory support. Similar results were observed by Gurbuz et al. [8]. No statistical difference in mean ventilation time was seen between obese and non obese patients in some previous reports [30] [31]. In our case series, obesity was not independently correlated with prolonged mechanical ventilation.

Obese patients undergoing CABG are reported to have an increased intensive care unit stay [32] [33] [34]. In recent study, Ranucci [35] and Khairudin [36] found that obese patients are at higher risk for postoperative hypoxia and prolonged ICU stay. In contrast to the published literature, Alam et al. [27] and Demir et al. [37] reported comparable ICU stay and hospital stay times in obese and non obese patients after CABG. There are disparate results on the association between the obesity and postoperative renal insufficiency. In our study, ob- 
ese patients did not develop postoperative renal dysfunction more than non obese and our results accords with recent series [37] [38]. But other investigators have linked obesity to an increased risk of postoperative renal dysfunction [8] [39] [40]. The incidence of surgical site infection after CABG is increased in obese compared to normal weight patients [22] [41] [42] [43]. In our study, obese patients developed mediastinitis more than non obese patients but it did not reach statistical significance. These results are in agreement with various reports [27] [31] [44]. Although some studies have suggested that obesity is associated with an increased risk of perioperative AMI [42] [45], our results noted lower incidence of AMI in obese patients compared with non obese patients $(p=0.02)$. In our study, chest tube drainage among the two groups was similar and no significant difference in the bleeding reexploration was observed. Similar finding have been described previously [11] [23] [46]. Although not proven, it revealed that obesity was protective for postoperative hemorrhage.

This association can be explained by hyper coagulopathy seen in obese patients due to increased levels of endothelial dysfunction and inhibition of fibrinolytic pathways [10] [47]. The literature regarding transfusion is controversial. Only two studies have evaluated product transfusion rates in obese patients after cardiac surgery. Uva et al. [48] found an increased need for transfusion while Ranucci et al. [49] found a lower incidence of transfusion. Obese patients in our cohort did not require more product transfusions than non obese patients.

Our study presents some limitations that should be kept in mind while interpreting the results. First, the most important was its retrospective design and conducted in a single-centre. Second, BMI may not be the best tool to define obesity. Yang [50] has suggested that the waist circumference or the waist-to-hip ratio seem to be a better measure to define obesity, but these data were not available in our database. Third, there could be other factors that may influence immediate results. Our cohort accounted heterogeneous clinical profile. Half of obese patients were diabetic and 58\% have hypertension, $47 \%$ have hyperlipedemia and it was well know that metabolic syndrome was an independent risk factor for postoperative adverse outcome. But this population was not studied alone. Finally, the current study includes only in hospital data. It lacks mid-term and long-term follow-up which could give more reliable results.

\section{Conclusions}

This study shows that obesity doses not affect the risk of perioperative death after coronary artery bypass graft and it is not associated with increased postoperative complications when compared to non-obese patients.

\section{Declarations}

\section{Ethics Approval and Consent to Participate}

The study was conducted in accordance with the ethical rules of the Helsinki Declaration and Good Clinical Practice. The study protocol was approved by 
Mohammed V University medical-ethical committees.

\section{Conflict of Interests}

The authors declare that they have no conflict of interests.

\section{Consent for Publication}

All other authors have read the manuscript and have agreed to submit it in its current form for consideration for publication in the journal.

\section{Funding}

We declared that the present research did not receive subvention or any funding from elsewhere source, private or public.

\section{References}

[1] Flegal, K.M., Carroll, M.D., Ogden, C.L. and Johnson, C.L. (2002) Prevalence and Trends in Obesity among US Adults, 1999-2000. Journal of the American Medical Association, 288, 1723-1727. https://doi.org/10.1001/jama.288.14.1723

[2] Seidell, J.C. (2002) Prevalence and Time Trends of Obesity in Europe. Journal of Endocrinological Investigation, 25, 816-822. https://doi.org/10.1007/BF03344045

[3] Chaves, V.L.V., Freese, E., Lapa, T.M., Cesse, E.A.P. and Vasconcelos, A.L.R. (2010) Evoluçãoespaço-temporal dosobrepeso e da obesidadeemadolescentesmasculinosBrasileiros, 1980 a 2005. [Temporal Evolution of Overweight and Obesity among Brazilian Male Adolescents, 1980-2005.] Cadernos de Saúde Pública, 26, 1303-1313. https://doi.org/10.1590/S0102-311X2010000700009

[4] Calle, E.E., Thun, M.J., Petrelli, J.M., Rodriguez, C. and Heath Jr., C.W. (1999) Bodymass. Index and Mortality in a Prospective Cohort of U.S Adults. The New England Journal of Medicine, 341, 1097-1105. https://doi.org/10.1056/NEJM199910073411501

[5] Todd Miller, M., Lavie, C.J. and White, C.J. (2008) Impact of Obesity on the Pathogenesis and Prognosis of Coronary Heart Disease. Journal of the Cardiometabolic Syndrome, 3, 162-167. https://doi.org/10.1111/j.1559-4572.2008.00004.x

[6] Moulton, M.J., Creswell, L.L., Machey, M.E., Cox, J.L. and Rosenbloom, M. (1996) Obesity Is Not a Risk Factor for Significant Adverse Outcome after Cardiac Surgery. Circulation, 94, 1187-1192.

[7] Koshal, A., Hendry, P., Raman, S.V. and Keon, W.J. (1985) Should Obese Patients Not Undergo Coronary Artery Surgery? Canadian Journal of Surgery, 28, 331-334.

[8] Gürbüz, H.A., Durukan, A.B., Salman, N., Uçar, H.I. and Yorgancioğlu, C. (2014) Obesity Is Still a Risk Factor in Coronary Artery Bypass Surgery. Anadolu Kardiyoloji Dergisi, 14, 631-637. https://doi.org/10.5152/akd.2014.4954

[9] Ardeshiri, M., Faritous, Z., OjaghiHaghighi, Z., Hosseini, S. and Baghaei, R. (2014) Effect of Obesity on Mortality and Morbidity after Coronary Artery Bypass Grafting Surgery in Iranian Patients. Anesthesiology and Pain Medicine, 4, e18884.

[10] Birkmeyer, N.J., Charlesworth, D.C., Hernandez, F., Leavitt, B., Marrin, C., Morton, J., Olmstead, E. and O'Connor, G. (1998) Obesity and Risk of Adverse Outcomes Associated with Coronary Artery Bypass Surgery. Circulation, 97, 1689-1694. https://doi.org/10.1161/01.CIR.97.17.1689 
[11] Gruberg, L., Mercado, N., Milo, S., Boersma, E., Disco, C., van Es, G., Lemos, P., Tzvi, M., Wijns, W., Unger, F., Beyar, R. and Serruys, P. (2005) Impact of Body Mass Index on the Outcome of Patients with Multivessel Disease Randomized to Either Coronary Artery Bypass Grafting or Stenting in the ARTS Trial: The Obesity Paradox II? American Journal of Cardiology, 95, 439-444.

[12] Ao, H., Wang, X., Xu, F., Zheng, Z., Chen, M., et al. (2014) The Impact of Body Mass Index on Short- and Long-Term Outcomes in Patients Undergoing Coronary Artery Graft Bypass. PLoS ONE, 9, e95223. https://doi.org/10.1371/journal.pone.0095223

[13] Shahabuddin, S., Perveen, S., Furnaz, S., Fatimi, S., Sami, S. and Sharif, H. (2013) Body Mass Index-Predictor of Outcome after Coronary Artery Bypass Grafting. Asian Cardiovascular and Thoracic Annals, 21, 176-180. https://doi.org/10.1177/0218492312451165

[14] Le-Bert, G., Santana, O., Pineda, A.M., Zamora, C., Lamas, G.A. and Lamelas, J. (2011) The Obesity Paradox in Elderly Obese Patients Undergoing Coronary Artery Bypass Surgery. Interactive Cardio Vascular and Thoracic Surgery, 2, 124-127. https://doi.org/10.1510/icvts.2010.256677

[15] Atalan, N., Fazlioğullari, O., Kunt, A.T., Başaran, C., Gurer, O., Sitilci, T., et al. (2012) Effect of Body Mass Index on Early Morbidity and Mortality after Isolated Coronary Artery Bypass Graft Surgery. Journal of Cardiothoracic and Vascular Anesthesia, 26, 813-817. https://doi.org/10.1053/j.jvca.2012.01.033

[16] Echahidi, N., Pibarot, P., Després, J.P., Daigle, J.M., Mohty, D., Voisine, P. Baillot, R. and Mathieu, P. (2007) Metabolic Syndrome Increases Operative Mortality in Patients Undergoing Coronary Artery Bypass Grafting Surgery. Journal of the American College of Cardiology, 50, 843-851.

[17] Zabetian, A., Hadaegh, F. and Azizi, F. (2007) Prevalence of Metabolic Syndrome in Iranian Adult Population, Concordance between the IDF with the ATPIII and the WHO Definitions. Diabetes Research and Clinical Practice, 77, 251-257.

[18] Nanan, D.J. (2002) The Obesity Pandemic-Implication for Pakistan. Journal of the Pakistan Medical Association, 52, 342-346.

[19] Eagle, K.A., Guyton, R.A., Davidoff, R., Ewy, G.A., Fonger, J., Gardner, T.J., Gott, J.P., Herrmann, H.C., Marlow, R.A., Nugent, W.C., O’Connor, G.T., Orszulak, T.A., Rieselbach, R.E., Winters, W.L., Yusuf, S., Gibbons, R.J., Alpert, J.S., Eagle, K.A., Garson, J.A., Gregoratos, G., Russell, R.O. and Smith, J.S.C. (1999) ACC/AHA Guidelines for Coronary Artery Bypass Graft Surgery: A Report of the American College of Cardiology/American Heart Association Task Force on Practice Guidelines (Committee to Revise the 1991 Guidelines for Coronary Artery Bypass Graft Surgery). American College of Cardiology/American Heart Association. Journal of the American College of Cardiology, 34, 1262-1347.

[20] Parsonnet, V., Dean, D. and Bernstein, A.D. (1989) A Method of Uniform Stratification of Risk for Evaluating the Results of Surgery in Acquired Adult Heart Disease. Circulation, 79, I3-I12.

[21] Nashef, S.A., Roques, F., Michel, P., Gauducheau, E., Lemeshow, S. and Salamon, R. (1999) European System for Cardiac Operative Risk Evaluation (EuroSCORE). European Journal of Cardio-Thoracic Surgery, 16, 9-13.

[22] Kim, J., Hammar, N., Jakobsson, K., Luepker, R.V., McGovern, P.G. and Ivert, T. (2003) Obesity and the Risk of Early and Late Mortality after Coronary Artery Bypass Graft Surgery. American Heart Journal, 146, 555-560.

[23] Gurm, H.S., Whitlow, P.L. and Kip, K.E. (2002) The Impact of Body Mass Index on 
Short- and Long-Term Outcomes in Patients Undergoing Coronary Revascularization: Insights from the Bypass Angioplasty Revascularization Investigation (BARI). Journal of the American College of Cardiology, 39, 834-840.

[24] Perrotta, S., Nilsson, F., Brandrup-Wognsen, G. and Jeppsson A. (2007) Body Mass Index and Outcome after Coronary Artery Bypass Surgery. The Journal of Cardiovascular Surgery, 48, 239-245.

[25] Baslaim, G., Bashore, J. and Alhoroub, K. (2008) Impact of Obesity on Early Outcomes after Cardiac Surgery: Experience in a Saudi Arabian Center. Annals of Thoraacic and Cardiovascular Surgery, 14, 369-375.

[26] Oreopoulos, A., Padwal, R., Norris, C.M., Mullen, J.C., Pretorius, V. and Kalantar-Zadeh, K. (2008) Effect of Obesity on Short- and Long-Term Mortality Postcoronary Revascularization: A Meta-Analysis. Obesity (Silver Spring), 16, 442-450. https://doi.org/10.1038/oby.2007.36

[27] Alam, M., Siddiqui, S., Lee, W., Elayda, M.A., Nambi, V., Yang, E.Y., et al. (2011) Isolated Coronary Artery Bypass Grafting in Obese Individuals: A Propensity Matched Analysis of Outcomes. Circulation Journal, 75, 1378-1385.

https://doi.org/10.1253/circj.CJ-10-1129

[28] Reeves, B.C., Ascione, R., Chamberlain, M.H. and Angelini, G.D. (2003) Effect of Body Mass Index on Early Outcomes in Patients Undergoing Coronary Artery Bypass Surgery. Journal of the American College of Cardiology, 42, 668-676.

[29] Saleh, H.Z., Shaw, M., Al-Rawi, O., Yates, J., Pullan, D.M., Chalmers, J.A., et al. (2012) Outcomes and Predictors of Prolonged Ventilation in Patients Undergoing Elective Coronary Surgery. Interactive CardioVascular and Thoracic Surgery, 15, 51-56. https://doi.org/10.1093/icvts/ivs076

[30] Engel, A.M., McDonough, S. and Smith, J.M. (2009) Does an Obese Body Mass Index Affect Hospital Outcome after Coronary Artery Bypass Graft Surgery? The Annals of Thoracic Surgery, 88, 1793-1800.

[31] Farsky, P.S., Graner, H., Duccini, P., ZandonadiEda, C., Amato, V.L., Anger, J., et al. (2011) Risk Factors for Sternal Wound Infections and Application of the STS Score in Coronary Artery Bypass Surgery. Revista Brasileira de Cirurgia Cardiovascular, 26, 624-629. https://doi.org/10.5935/1678-9741.20110054

[32] Villavicencio, M.A., Sundt, T.M. III, Daly, R.C., Dearani, J., McGregor, C., Mullany, C., Orszulack, T., Puga, F. and Schaff, H. (2007) Cardiac Surgery in Patients with Body Mass Index of 50 or Greater. The Annals of Thoracic Surgery, 83, 1403-1411.

[33] Ghotkar, S.V., Grayson, A.D., Fabri, B.M., Dihmis, W.C. and Pullan, D.M. (2006) Preoperative Calculation of Risk for Prolonged Intensive Care Unit Stay Following Coronary Artery Bypass Grafting. Journal of Cardiothoracic Surgery, 1, 14. https://doi.org/10.1186/1749-8090-1-14

[34] Sun, X., Hill, P.C., Bafi, A.S., Garcia, J.M., Haile, E., Corso, P.J. and Boyce, S.M. (2009) Is Cardiac Surgery Safe in Extremely Obese Patients (Body Mass Index 50 or Greater)? The Annals of Thoracic Surgery, 87, 540-547.

[35] Ranucci, M., Ballotta, A., La Rovere, M.T. and Castelvecchio, S. (2014) Postoperative Hypoxia and Length of Intensive Care Unit Stay after Cardiac Surgery: The Underweight Paradox? PLoS ONE, 9, e93992. https://doi.org/10.1371/journal.pone.0093992

[36] Zuraida, K. (2012) Determinants of Prolonged Stay after Coronary Artery Bypass Graft Surgery. Procedia Social and Behavioral Sciences, 36, 87-95.

[37] Demir, A., Aydınlı, B., Guclu, C.Y., Yazıcıoğlu, H., Sarac, A., Elhan, A.H., et al. 
(2012) Obesity and Postoperative Early Complications in Open Heart Surgery. Journal of Anesthesia, 26, 702-710. https://doi.org/10.1007/s00540-012-1393-7

[38] Tokmakoğlu, H. (2010) Operative and Early Results of Coronary Artery Bypass Grafting in Female Patients in Different Body Mass Indexes. Journal of Cardiothoracic Surgery, 5, 119. https://doi.org/10.1186/1749-8090-5-119

[39] Virani, S.S., Nambi, V., Lee, V.V., Elayda, M.A., Pan, W., Petersen, L.A., Wilson, J.M., Willerson, J.T. and Ballantyne, C.M. (2009) Obesity: An Independent Predictor of In-Hospital Postoperative Renal Insufficiency among Patients Undergoing Cardiac Surgery? Texas Heart Institute Journal, 36, 540-545.

[40] Prabhakar, G., Haan, C.K., Peterson, E.D., Coombs, L.P., Cruzzavala, J.L. and Murray, G.F. (2002) The Risks of Moderate and Extreme Obesity for Coronary Artery Bypass Grafting Outcomes: A Study from the Society of Thoracic Surgeons' Database. The Annals of Thoracic Surgery, 74, 1125-1131.

[41] Swenne, C.L., Lindholm, C., Borowiec, J. and Carlsson, M. (2004) Surgical-Site Infections within 60 Days of Coronary Artery By-Pass Graft Surgery. Journal of Hospital Infection, 57, 14-24.

[42] Prasad, U.S., Walker, W.S., Sang, C.T., Campanella, C. and Cameron, E.W. (1991) Influence of Obesity on the Early and Long Term Results of Surgery for Coronary Artery Disease. European Journal of Cardio-Thoracic Surgery, 5, 67-72.

[43] Lindhout, A.H., Wouters, C.W. and Noyez, L. (2004) Influence of Obesity on In-Hospital and Early Mortality and Morbidity after Myocardial Revascularization. European Journal of Cardio-Thoracic Surgery, 26, 535-541.

[44] Ledur, P., Almeida, L., Pellanda, L.C. and Schaan, B.D. (2011) Predictors of Infection in Post-Coronary Artery Bypass Surgery. Revista Brasileira de Cirurgia Cardiovascular, 26, 190-196.

[45] Lopez-Delgado, J.C., Esteve, F., Manez, R., Torrado, H., Carrio, M.L., Rodríguez-Castro, D., Farrero, E., Javierre, C., Skaltsa, K. and Ventura, J.L. (2015) The Influence of Body Mass Index on Outcomes in Patients Undergoing Cardiac Surgery: Does the Obesity Paradox Really Exist? PLOS ONE, 10, e0118858. https://doi.org/10.1371/journal.pone.0118858

[46] Wigfield, C.H., Lindsey, J.D., Muñoz, A., Chopra, P.S., Edwards, N.M. and Love, R.B. (2006) Is Extreme Obesity a Risk Factor for Cardiac Surgery? An Analysis of Patients with a BMI $>$ or $=40$. European Journal of Cardio-Thoracic Surgery, 29, 434-440.

[47] Jimenez Rivera, J.J., Iribarren, J.L., Raya, J.M., Nassar, I., Lorente, L., Perez, R., et al. (2007) Factors Associated with Excessive Bleeding in Cardiopulmonary Bypass Patients: A Nested Case-Control Study. Journal of Cardiothoracic Surgery, 2, 17. https://doi.org/10.1186/1749-8090-2-17

[48] Uva, M.S., Rodrigues, V., Monteiro, N., Manuel Pedro, A., Caria, R., Mesquita, A., Fernandes, J., Pinho, J., Bau, J. and Magalhaes, P. (2002) Cardiac Surgery and Morbid Obesity. Revista Portuguesa de Cardiologia, 21, 255-264.

[49] Ranucci, M., Cazzaniga, A., Soro, G., Morricone, L., Enrini, R. and Caviezel, F. (1999) Obesity and Coronary Artery Surgery. Journal of Cardiothoracic and Vascular Anesthesia, 13, 280-284.

[50] Yang, L., Kuper, H. and Weiderpass, E. (2008) Anthropometric Characteristics as Predictors of Coronary Heart Disease in Women. Journal of Internal Medicine, 264, 39-49. https://doi.org/10.1111/j.1365-2796.2007.01907.x 